\title{
Health and Clinical Management - Impact on Clinical Outcome
}

\section{Findings from the Section on Health and Clinical Management}

\author{
J. Bergmann, Managing Editor for the IMIA Yearbook Section on Health and Clinical Management \\ Technical University of Braunschweig, Institute of Medical Informatics, Braunschweig, Germany
}

\begin{abstract}
Summary
Objectives: To summarize current excellent research in the field of health and dinical management.

Method:Synopsis of the articles selected for the IMIA Yearbook 2007.

Results: Five articles from international peer reviewed journals were selected for the section on health and dinical management of the IMIA Yearbook 2007. They represent outstanding research on computerized provider order entry, computer applications in the field of translational medicine, time efficiency of electronic health records, and deliverance of telemedicine.

Conclusions: In the field of health and dinical management, clinical outcome of computer-supported healthcare, cost-benefit analysis, and barriers and facilitators for technology adoption are still current research topics.

\section{Keywords \\ Medical informatics; International Medical Informatics Association; yearbook; patient care management; technology assessment, biomedical \\ Geissbuhler A, Haux R, KulikowskiC, editors. IMIA Yearbook of Medical Informatics 2007. Methods InfMed 2007; 46Supp 1:30-3}

\section{Introduction}

The best paper selection of articles for the section 'Health and Clinical Management' of the IMIA Yearbook 2007 presents examples of excellent research focusing on concepts and impact of health and clinical management.

Five excellent articles were selected from international peer reviewed journals in the fields of medicine and medical informatics. The articles mainly contribute to the discussion about impact of computer applications on healthcare. Topics are computer applications for translational medicine, computerized provider order entry (CPOE), time efficiency of electronic health records, and case management delivered to patients using telemedicine.

Table 1 presents the selected papers. A brief content summary of the selected best papers can be found in the appendix of this report.

\section{Results and Discussion}

The best paper selection documents significant topics in health informatics of the past year. A key issue in 2006 was the discussion about unexpected adverse effects of CPOE implementations, which was triggered by a study of Han et al. [1]. Subsequent comments and papers addressed the design of this study, assignable causes for the increased mortality found, and conclu- sions to draw from those results. An afterwards conducted study of Del Beccaro et al. in a different environment resulted in a contradictory finding [2]. A following discussion of experts came to the conclusion, that the two studies are not comparable [3]. From the research of the past years it becomes evident, that the positive potential of CPOE systems can turn into negative, if the system is implemented or used poorly and does not consider the socio-technical environment to an adequate extent [4].

Among the various success factors for implementing CPOE in clinical settings, time efficiency is an important aspect associated with the adoption of this technology by health professionals. A systematic literature review by Poissant et al. now provides evidence, that using $\mathrm{CPOE}$ is time consuming for physicians compared with traditional working processes in paper-based systems [5]. The study also reveals, that the type of computerized system, bedside or central station desktop, influences the documentation time of health professionals, and that the goal of decreasing documentation time with an electronic health record system is still difficult to achieve.

Beyond time efficiency as a direct cost factor for the respective organization, the cost-benefit analysis in [6] demonstrates the need for a more comprehensive performance analysis of computerbased interventions. The study is 
Table 1 Best paper selection of articles for the IMIA Yearbook of Medical Informatics 2007 in the section 'Health and Clinical Management'. The articles are listed in alphabetical order of the first author's surname.

\section{Section}

Health and Clinical Management

- Feldman PH, Murtaugh CM, Pezzin LE, McDonald MV, Peng TR. Just-in-time evidence-based e-mail "reminders" in home health care: impact on patient outcomes. Health Serv Res 2005;40(3):865-85

- Han YY, Carcillo JA, Venkataraman ST, Clark RS, Watson RS, Nguyen TC, et al. Unexpected increased mortality after implementation of a commercially sold computerized physician order entry system. Pediatrics 2005;116(6):1506-12.

- Pizziferri L, Kittler AF, Volk LA, Honour MM, Gupta S, Wang S, et al. Primary care physician time utilization before and after implementation of an electronic health record: a time-motion study. J Biomed Inform 2005;38(3):176-88.

- Poissant L, Pereira J, Tamblyn R, Kawasumi Y. The impact of electronic health records on time efficiency of physicians and nurses: a systematic review. J Am Med Inform Assoc 2005;12(5):505-16.

- Shea S, Weinstock RS, Starren J, Teresi J, Palmas W, Field L, et al. A randomized trial comparing telemedicine case management with usual care in older, ethnically diverse, medically underserved patients with diabetes mellitus. J Am Med Inform Assoc 2006;13(1):40-51.

dedicated to the translation of evidencebased medical research into practice and shows an improvement of patient outcome, achieved with computerized reminders to home care nurses. Coming to the conclusion, that a single e-mail reminder is more cost-effective than the "augmented intervention" (see study summary below), the authors of [6] demonstrate the need for sophisticated cost estimations of different implementation alternatives.

\section{Acknowledgement}

We greatly acknowledge the support of Martina Hutter and of the reviewers in the selection process of the IMIA Yearbook.

\section{References}

1. Y.Y. Han, J.A. Carcillo, S.T. Venkataraman, R.S. Clark, R.S. Watson, T.C. Nguyen, et al. Unexpected increased mortality after implementation of a commercially sold computerized physician order entry system. Pediatrics 2005;116(6):1506-12.

2. M.A. Del Beccaro, H.E. Jeffries, M.A. Eisenberg, E.D. Harry. Computerized provider order entry implementation: no association with increased mortality rates in an intensive care unit. Pediatrics 2006; 118(1):290-5.

3. E. Ammenwerth, J. Talmon, J.S. Ash, D.W. Bates, M.C. Beuscart-Zephir, A. Duhamel, et al. Impact of CPOE on mortality rates - contradictory findings, important messages. Methods Inf Med 2006;45(6):586-93.

4. E. Coiera, J. Westbrook, J. Wyatt. The safety and quality of decision support systems. Methods Inf Med 2006;45 Suppl 1:20-5.

5. L. Poissant, J. Pereira, R. Tamblyn, Y. Kawasumi. The impact of electronic health records on time efficiency of physicians and nurses: a systematic review. J Am Med Inform Assoc 2005;12(5):505-16.

6. L. Pizziferri, A.F. Kittler, L.A. Volk, M.M. Honour, S. Gupta, S. Wang, et al. Primary care physician time utilization before and after implementation of an electronic health record: a time-motion study. J Biomed Inform 2005;38(3):176-88.

7. C.M. Murtaugh, L.E. Pezzin, M.V. McDonald, P.H. Feldman, T.R. Peng. Just-in-time evidencebased e-mail "reminders" in home health care: impact on nurse practices. Health Serv Res 2005;40(3):849-64.

8. P.H. Feldman, C.M. Murtaugh, L.E. Pezzin, M.V. McDonald, T.R. Peng. Just-in-time evidence-based e-mail "reminders" in home health care: impact on patient outcomes. Health Serv Res 2005; 40(3):865-85

9. J.S. Ash, P.N. Gorman, M. Lavelle, P.Z. Stavri, J. Lyman, L. Fournier, et al. Perceptions of physician order entry: results of a cross-site qualitative study. Methods Inf Med 2003;42(4):313-23.

10. S. Shea, R.S. Weinstock, J. Starren, J. Teresi, W. Palmas, L. Field, et al. A randomized trial comparing telemedicine case management with usual care in older, ethnically diverse, medically underserved patients with diabetes mellitus. J Am Med Inform Assoc 2006;13(1):40-51.

\section{Correspondence to:}

Joachim Bergmann

Technical University of Braunschweig

Institute of Medical Informatics

Muehlenpfordtstr. 23

D-38106 Braunschweig

Germany

Tel: +495313919506

Fax: + 495313919502

E-mail: j.bergmann@mi.tu-bs.de
Appendix: Content Summaries of Selected Best Papers for the IMIA Yearbook 2007, Section Health and Clinical Management*

\author{
Feldman PH, Murtaugh CM, Pezzin LE, \\ McDonald MV, Peng TR \\ Just-in-time evidence-based e-mail \\ "reminders" in home health care: impact on \\ patient outcomes
}

\section{Health Serv Res 2005;40(3):865-85}

Heart failure patients often are referred to home care after a hospital stay [7]. The assigned home health nurse usually follows an individual care plan and instructs the patient for self management. An adoption of evidence-based practices by the nurse can be enforced with just-in-time recommendations, which are sent to the nurse every time starting to care for a new patient [7]. Patient outcome and cost-effectiveness of just-in-time reminders in case of heart failure patients are reported in the work of Feldman et al. [8]. The study employs a controlled trial with two intervention groups and a partly randomized and blinded design. Nurses of the basic intervention group received an email highlighting specific clinical practice guidelines, which have been determined by an expert panel. Nurses of the augmented intervention group additionally received paper-based information material and a subsequent outreach inquiring about the patient and possible issues to discuss. Outcome measures were the patient's self-management behavior, clinical and func-

* The complete papers can be accessed in the Yearbook's full electronic version, provided that permission has been granted by the copyright holder(s) 
tional status and quality of life, and utilized healthcare services during follow-up period. In combination with the administrative records, cost estimates have been developed. The authors were able to assess an improvement of clinical and functional outcomes compared to usual care in both intervention groups and a higher quality of life score for the basic intervention. Self management behavior regarding medication knowledge, diet and weight monitoring was also improved. The basic intervention has shown to be more cost-effective than the augmented intervention, while both interventions have led to an increased use of healthcare-related services.

\section{Han YY, Carcillo JA, Venkataraman ST, Clark RS, Watson RS, Nguyen TC, Bayir H, Orr RA \\ Unexpected increased mortality after implementation of a commercially sold computerized physician order entry system \\ Pediatrics 2005;116(6):1506-12}

Since the Institute of Medicine has published a report on the potential of computerized physician order entry in 1999, an ongoing interest in clinical outcome of CPOE systems and especially medication ordering and decision support functions can be perceived. Besides positive expectancies regarding e.g. allergy checks, dose calculation and medication reminders, the necessity for careful design of these functions and their implementation in clinical routine is known [9]. In this context, the result of the CPOE study of Han et al. [1] raised an intensive discussion in the past year [3]. The study reports an unexpected increased mortality in coincidence with the implementation of a commercially sold CPOE application in a regional pediatric referral center. The authors have compared the 13month period before with the 5-month period after introduction of the $\mathrm{CPOE}$ add-on module. The data of 1942 children, who were admitted via interfacility transport to the center, were extracted from the database of the transport team and retrospectively analyzed. Assessment of the mortality rate with univariate analysis revealed an increase from $2.80 \%$ before to $6.57 \%$ after implementation of the CPOE module. Also using multivariate analysis method, CPOE is associated with an increased odds of mortality. The authors conclude in a qualitative discussion, that the observed increase in mortality is likely to be a consequence of an inadequate implementation of the $\mathrm{CPOE}$ module. The application was not sufficiently customized for the present clinical workflow and induced changes which are well known as risk factors facilitating medication errors [3], especially fundamental changes in the staff interaction, delays through the order entry process and less face-to-face communications about medications.

Pizziferri L, Kittler AF, Volk LA, Honour MM, Gupta S, Wang S, Wang T, Lippincott M, Li Q, Bates DW

Primary care physician time utilization before and after implementation of an electronic health record: a time-motion study

\section{J Biomed Inform 2005;38(3):176-88}

Concerns about time efficiency of electronic health record (EHR) systems for documentation-related tasks are often barriers to implementation or adoption of this technology. Especially physicians commonly argue against EHRs, that paper-based documentation is faster and easier to use in clinical processes. New significant results about time efficiency of an EHR system are presented by Pizziferri et al. [6]. The authors evaluated duration of clinical activities in five primary care clinics using a time-motion methodology. Twenty phy- sicians were observed before and after implementation of an EHR. During the observations, each activity was classified and start and stop time recorded. Additional surveys were used to assess physicians' perceptions regarding the effect of the EHR on their clinical work. As a main result of the observation part it was found, that the EHR required no additional physician time during clinical sessions, it even slightly decreased the time spent per patient by $0.5 \mathrm{~min}$ utes. In contrast, the surveys revealed, that the majority of the physicians perceived an increased time to spend for documentation tasks after implementation. On the other side, the physicians reported that EHR implementation results in quality improvement and facilitates communication and access to patient information. The authors conclude, that the implemented EHR system does not require more time during clinical sessions, while the impact on non-clinic time requires further research.

\section{Poissant L, Pereira J, Tamblyn R, Kawasumi Y The impact of electronic health records on time efficiency of physicians and nurses: a systematic review}

\section{J Am Med Inform Assoc 2005; 12(5):505-16}

Poissant et al. [5] systematically reviewed the literature to assess the impact of electronic health records on documentation time of health professionals. From a total of 628 papers, 23 studies of the past two decades met the inclusion criteria and were classified for design, methodology, type of computerized system, and sample characteristics. As the key results of each study, documentation time using the paperbased system and documentation time using the computer application were extracted. From these measures, relative time differences were computed and combined with a weighted average 
approach to determine conclusions about the different types of computerized systems. The results indicate, that nurses will more likely profit from improvements in time efficiency by EHRs than physicians. Central station desktops for CPOE systems were found to increase the documentation time by a weighted average time difference of $238.4 \%$. The authors conclude, that the goal of decreasing documentation time with an EHR is difficult to achieve. A shift from focusing on user's time efficiency to overall efficiency of the organization may facilitate the adoption of EHR systems, especially by physicians.

\section{Shea S, Weinstock RS, Starren J, Teresi J, Palmas W, Field L, Morin P, Goland R, Izquierdo RE, Wolff LT, Ashraf M, Hilliman C, Silver S, Meyer S, Holmes D, Petkova E, Capps L, Lantigua RA \\ A randomized trial comparing telemedicine case management with usual care in older, ethnically diverse, medically underserved patients with diabetes mellitus}

J Am Med Inform Assoc 2006;13(1):40-51
A broad variety of electronic services supporting healthcare across distances is available comprising teleconsultation, remote monitoring, electronic messaging, electronic health records, web-based education, and many other technologies. Shea et al. studied the clinical outcome of the integrated telemedical approach within the IDEATel project [10]. A randomized controlled trial was conducted among 1665 older diabetes patients from medically underserved areas, with a blinded design for collecting the outcome data. Patients of the intervention group were equipped with a home telemedicine unit (HTU) and received a case management service additionally to usual care. The HTU offers functions for videoconferencing, remote monitoring of glucose and blood pressure, access to a clinical web portal for data management and communications, and access to a website for educational purposes. Study endpoints were hemoglobin Alc (HbAlc), blood pressure (BP), and LDL cholesterol levels, which were obtained at the baseline investigation and at a one-year follow-up examination. The authors found that the integrated telemedical approach delivering diabetes case management improved all three values $(\mathrm{HbAlc}, \mathrm{BP}$, and $\mathrm{LDL}$ cholesterol) compared to usual care. They also found evidence for improvements in usual care measured by $\mathrm{HbAlc}$, which are supposed to result from national educational and quality improvement programs. The adjusted net reduction of $\mathrm{HbAlc}$ favoring the intervention group was $0.18 \%$. In the subgroup of patients with a baseline characteristic of HbAlc, which are supposed to result from national educational and quality improvement programs. The adjusted net reduction of $\mathrm{HbAlc}$ favoring the intervention group was $0.18 \%$. In the subgroup of patients with a baseline characteristic of $\mathrm{HbAlc} \geq 7 \%$, this improvement was more explicit with $0.32 \%$. 